\title{
Molecular genetic and biochemical evidence for adaptive evolution of leaf abaxial epicuticular wax crystals in the genus Lithocarpus (Fagaceae)
}

Chih-Kai Yang ${ }^{1,2+}$, Bing-Hong Huang ${ }^{1+}$, Shao-Wei Ho ${ }^{1}$, Meng-Yuan Huang ${ }^{3}$, Jenn-Che Wang ${ }^{1}$, Jian Gao ${ }^{4}$ and Pei-Chun Liao ${ }^{1 *}$ (D)

\begin{abstract}
Background: Leaf epicuticular wax is an important functional trait for physiological regulation and pathogen defense. This study tests how selective pressure may have forced the trait of leaf abaxial epicuticular wax crystals (LAEWC) and whether the presence/absence of LAEWC is associated with other ecophysiological traits. Scanning Electron Microscopy was conducted to check for LAEWC in different Lithocarpus species. Four wax biosynthesis related genes, including two wax backbone genes ECERIFERUM 1 (CER1) and CER3, one regulatory gene CER7 and one transport gene CER5, were cloned and sequenced. Ecophysiological measurements of secondary metabolites, photosynthesis, water usage efficiency, and nutrition indices were also determined. Evolutionary hypotheses of leaf wax character transition associated with the evolution of those ecophysiological traits as well as species evolution were tested by maximum likelihood.
\end{abstract}

Results: Eight of 14 studied Lithocarpus species have obvious LAEWC appearing with various types of trichomes. Measurements of ecophysiological traits show no direct correlations with the presence/absence of LAEWC. However, the content of phenolic acids is significantly associated with the gene evolution of the wax biosynthetic backbone gene CER1, which was detected to be positively selected when LAEWC was gained during the late-Miocene-toPliocene period.

Conclusions: Changes of landmass and vegetation type accelerated the diversification of tropical and subtropical forest trees and certain herbivores during the late Miocene. As phenolic acids were long thought to be associated with defense against herbivories, co-occurrence of LAEWC and phenolic acids may suggest that LAEWC might be an adaptive defensive mechanism in Lithocarpus.

Keywords: Adaptive evolution, Leaf epicuticular wax, Lithocarpus, Physical defenses, Chemical defenses, Phylogenetic signal

\footnotetext{
* Correspondence: pcliao@ntnu.edu.tw

${ }^{\dagger}$ Chih-Kai Yang and Bing-Hong Huang contributed equally to this work.

${ }^{1}$ School of Life Science, National Taiwan Normal University, Postal address:

No. 88, Tingchow Rd. Sect. 4, Taipei 11677, Taiwan

Full list of author information is available at the end of the article
}

(c) The Author(s). 2018 Open Access This article is distributed under the terms of the Creative Commons Attribution 4.0 International License (http://creativecommons.org/licenses/by/4.0/), which permits unrestricted use, distribution, and reproduction in any medium, provided you give appropriate credit to the original author(s) and the source, provide a link to the Creative Commons license, and indicate if changes were made. The Creative Commons Public Domain Dedication waiver (http://creativecommons.org/publicdomain/zero/1.0/) applies to the data made available in this article, unless otherwise stated. 


\section{Background}

The evolution of a waterproof epidermis is considered important for plants' colonization of the land [1]. A waterproof epidermis trait, such as leaf epicuticular wax, is a kind of xeromorphic feature [2] which helps reduce the evapotranspiration rate and allows a plant to adapt to an arid environment $[2,3]$. In the case of leaf epicuticular wax, it thickens the boundary layer to reduce evapotranspiration, but its appearance may also reduce the absorption of $\mathrm{CO}_{2}$ and reduce photosynthesis efficiency. The partial pressure of $\mathrm{CO}_{2}$ is small (0.01 $0.036 \%$ ) and the heavier molecular weight of $\mathrm{CO}_{2}$ than $\mathrm{H}_{2} \mathrm{O}$ leads to a slower $\mathrm{CO}_{2}$ diffusion rate than evapotranspiration rate and so the appearance of leaf epicuticular wax is suggested as an advantageous feature for adapting to arid environments [4]. The accumulation of leaf epicuticular wax is thought to be regulated by light intensity and relative humidity, suggesting that the water regulation of epicuticular wax may be attributed to environmental signals [5]. In addition, the hydrophobic nature of epicuticular wax could decrease the contact area of water, causing water to drain more quickly [6] which, in turn, aids in the removal of dust, bacteria, and epiphytes (i.e. self-cleaning, the Lotus effect). Epicuticular wax may also help maintain the physical integrity of plant leaves by reducing damage caused by pathogens [7]. Therefore, it is suggested as an adaptive indicator of the physical defense of plants [8].

The biosynthesis of epicuticular wax occurs in epidermal cells, in which the very-long-chain-fatty-acids (VLCFAs) are synthesized in endoplasmic reticula. Following this is modification and regulation which synthesizes the precursor of wax. This is then transported to the outer membrane via the ATP-binding cassette $(\mathrm{ABC})$ transporter [9]. Upregulation of wax biosynthetic genes in Arabidopsis is a response to the water content of plants in the face of flooding or drought stress [9-12]. Transcriptomic comparisons between the domesticated tomato (Solanum lycopersicum) and the desert-adapted accession (Solanum pennellii) revealed differential expression in several wax biosynthetic related genes, including the ECERIFERUM1 (CER1), CER2, CER3, CER4, CER5-like, CER6, CER7, CER8, CER10, LIPID TRANSFER PROTEIN1 (LTP1), LTP2, WAX INDUCER1 (WIN1), etc. [13]. These wax-biosynthetic genes can be placed into three categories: the backbone genes, regulation genes, and transporters. For example, the backbone gene CER1 interacts with CER3 with both jointly responsible for the synthesis and modification of VLC-alkane [14]. CER3 catalyzes the VLC-acyl-CoAs to VLC-acyl and then CER1 transforms it to the VLC-alkanes [14]. In addition, both genes are also pleiotropic and involved in morphogenesis in the wax exine of pollen and adaxial epidermal cell wall [15, 16]. Furthermore, CER7 inhibits the RNA repressor of CER3 to positively affect the biosynthesis of VLC-alkanes
[17]. Heterodimers of CER5 and the ABC transporter $G$ family member 11 (ABCG11, also called white-brown complex homolog protein 11 , the WBC11) are involved in the exportation of wax components to apoplast [18]. The cer5 mutant of Arabidopsis revealed a lower content of epicuticular wax than the wild type [19], evidence that the expression of CER5 affects the phenotype of leaf epicuticular wax.

Geographic differentiation of epicuticular wax composition, e.g. the carbon number of alkane backbones of wax, is thought to be a consequence of local adaptation to environmental differences such as precipitation and temperature [20]. This implies that leaf epicuticular wax is a functional trait, defined as the morpho-physiophenological character contributing to environmental adaptation [21]. Functional traits are usually interdependent [22-24] and covariation among functional traits may reflect the causality or coordination between functional traits [22] which are adopted for maximizing performance in a given environment [25]. For example, a positive correlation was found between trichome density and latex production, and between $\mathrm{C}: \mathrm{N}$ ratio and leaf toughness in milkweeds (Asclepias spp.) [26]. The tradeoff between defensive characters, such as epicuticular wax, and growth-related characters, such as carbon, nitrogen, photosynthetic parameters, etc., is suggested as another interdependent relationship between functional traits [27-29]. The allocation of resources in physical and chemical defense was hypothesized to reduce unnecessary waste of resources, as another trade-off strategy for adaptation [30-32], or alternatively, was suggested as an integrated defense strategy against a wide range of herbivores [33].

The objective of this study was to test the adaptive hypothesis of leaf epicuticular wax in Lithocarpus and determine the relationship between leaf abaxial epicuticular wax crystal (LAEWC) and other functional traits. Genus Lithocarpus is a group of tropical and subtropical Asian tree species commonly known as stone oaks [34, 35] grouped with Castanopsis, Castanea, Quercus, and Chrysolepis [36, 37]. All of the Lithocarpus species whose chromosome numbers have been checked are reported to be $2 \mathrm{n}=$ 24 and are unlikely to be polyploids ([38]; The Index of Plant Chromosome Numbers, http://www.tropicos.org/ Project/IPCN). Roughly half the known species are locally endemic to mainland China, adjacent islands, and Borneo [39-41], suggesting the species of this genus are highly adaptable to environmental changes. The adaptive characteristic is revealed in phenotypes, such as differences in epicuticular wax crystals and trichomes on leaf surface [42, 43], and reflect environmental variations. Drastic climate change during middle-to-late Miocene to the Quaternary (Pliocene and Pleistocene) is suggested as a major force affecting the current distribution and diversification rate of 
Lithocarpus [44]. Past climate change attributed to glacial oscillations which had a major influence on temperature and precipitation, may have directly or indirectly affect plant growth due to limits on water usage and photosynthesis efficiency [45]. Here we use Lithocarpus as a way of answering the question of whether the trait variation of leaf epicuticular wax adaptively reflects environmental change with other co-varied ecophysiological traits.

After confirming the presence/absence of leaf epicuticular wax by microscopic observation, three questions were explored in this study: (1) Are LAEWC related genes adaptively evolved? (2) Is the presence/absence of LAEWC co-varied with ecophysiologically functional relevant traits (e.g. chemical defensive and photosynthetic characters)? (3) Is the presence/absence of LAEWC related to environmental variations? We also calculated the time when the positive selection of the trait took place as well as tested the phylogenetic signal (PS) of the ecophysiological traits and environmental factors with the species evolution and gene evolution for understanding the trends of co-evolution of these functional traits. This study integrates evidence from ecophysiological and climatic data with evolutionary genetic analyses to illustrate the adaptive evolution of LAEWC of Lithocarpus.

\section{Methods}

\section{Plant materials}

Fourteen Lithocarpus species grown in the Fushan Botanical Garden, a long-term ecological research (LTER) site for the subtropical forest in northern Taiwan, were collected for morphological, genetic, and ecophysiological surveys.

\section{Scanning electron microscopy}

Scanning Electron Microscopy (SEM) was conducted to check for the presence/absence of the epicuticular wax crystals on the leaf surfaces using the tabletop SEM TM3000 (Hitachi, Tokyo, Japan). Small pieces of fresh blades $(5 \mathrm{~mm} \times 5 \mathrm{~mm})$ between the leaf margin and midrib were cut for microscopic observation and at least two individuals were adopted for checking the presence/ absence of the epicuticular wax crystals at an accelerating voltage of $15 \mathrm{kV}$ in order to obtain high image resolution signals.

\section{Molecular techniques}

We sampled fresh leaves from one individual of each species, the fresh leaves were stored in the RNAguardian solution (MBGEN Bioscience, Taipei, Taiwan) at $-80{ }^{\circ} \mathrm{C}$. RNA extraction followed Gambino et al.'s [46] approach and removed sugars and polyphenols using CTAB lysis buffer and genomic DNA with TRIzol (Life Technologies
Corp. California, USA). In order to understand genetic variation and to test selective pressure by comparing the evolutionary rates of genes, four candidate genes involved in wax backbone synthesis (CER1 and CER3), regulation (CER7), and transportation (CER5) were chosen for cDNA sequencing. Other genes such as WIN1, waxy, and ECR which are also involved in wax synthesis failed to amplify and could not be used for this study. Therefore, only the four CER candidate genes were identified as LAEWC related genes in this study. Six wax-unrelated genes (CAP, DGD, ESRK, FAD, SAHH, and $S A M$ ) were also sequenced as reference genes from genomic DNA. All selected genes, including the four LAEWC related genes and six wax-unrelated genes, are homologous based on specific primer selection and multiple checks with by sequencing of the cloned amplified products. Primer sequences, sequence information including sequence length and percentage of coding region and GenBank accession numbers are listed in Additional files (Additional file 1: Table S1). These genes have functions in other tissues including pollen and adaxial epidermis in other plant species $[15,34]$ so we focus on those genes expressed in leaf tissue of species with and without LAEWCs. The amplified cDNA fragments were cloned using a yT\&A cloning kit (Yeastern Biotech, Taipei, Taiwan). Three clones from each species were chosen for subsequently sequencing and the M13F/ M13R were used as the primer for sequencing. Bidirectional DNA sequencing was conducted using ExoSAPIT (Thermo Fisher Scientific Inc., Waltham, MA, USA) and ABI BigDye 3.1 Terminator Cycle Sequencing Kit (Applied Biosystem, Foster City, CA, USA) and conducted by ABI PRISMH ${ }^{\circ}$ 3730XL DNA Sequencer (Perkin-Elmer, Foster City, CA, USA). Due to little variation in chromosome number in the Lithocarpus species (almost all reported species are $2 \mathrm{n}=24$, [38]; The Index of Plant Chromosome Numbers, http://www.tropicos.org/ Project/IPCN) and the unlikelihood of polyploidy, the possibility that different clones are homoeologs was not considered in this study. All sequences presented in this study were deposited in the NCBI GenBank under Accessions KY458808-KY458955.

\section{Genetic analyses}

DNA sequences were aligned and checked with the assistance of BioEdit [47]. The aligned sequences of every gene were used for phylogenetic reconstruction by the neighbor-joining (NJ) method, maximum-likelihood (ML) method, and Bayesian inference (BI) using MEGA 6.0 [48], PhyML 3.0 [49], and MrBayes 3.2 [50], respectively. For $\mathrm{NJ}$ tree reconstruction, the maximum composite likelihood model was used as the nucleotide substitution model and pairwise deletion was set for gap treatment. For PhyML, nearest neighbor interchange 
(NNI) was used for tree searching and approximate likelihood-ratio test (aLRT) for estimating branch support. For BI tree, two parallel Markov chain Monte Carlo (MCMC) simulations of 10 million generations with 10\% burn-in were used for obtaining the consensus tree. Six reference genes were also used for reconstructing the species tree. Due to the unavailability of the sequences of closest outgroup Chrysolepis, we chose Quercus robur, Castanea mollissima, and Fagus sylvatica as outgroup in BEAST 1.8.2 [51]. One-hundred million years ago (Mya) as the origin time of Fagaceae [52] and 60 Mya when Fagus and Castanea diverged [52] were used as calibration points for molecular dating under the lognormal relaxed molecular model. Yule's pure-birth speciation model was chosen as the speciation model for species tree reconstruction. One-thousand million MCMC generations with a sampling of every 10,000 generations were used in summary statistic. The character state of LAEWC was then mapped to the species tree for hypothesizing trait-shift events. It should be noted that while the outgroup $Q$. robur is coded as "absence" of LAEWC, most of Quercus species revealed "presence" [53]. The closest outgroup Chrysolepis reveals "absence" of LAEWC [54] but the sequences and materials of that outgroup were unavailable for this study, so we adopted Q. robur for rooting but kept the "absence" state in outgroup LAEWC.

In order to test the selection signals of the four LAEWC related genes, substitution rates of all nucleotides of a gene $(K)$, nonsynonymous nucleotide substitution rates $(K a)$ and synonymous substitution rates $(K s)$ of each LAEWC related gene were compared to that of reference genes. The dependent two-group Wilcoxon Signed Rank Test (WSRT) and simple linear regression (SLR) were used for testing the group differences between LAEWC related genes and reference genes. Due to the uncertainty of the ancestral state of LAEWC in Lithocarpus, we developed three scenarios which consider either the presence or absence of LAEWC. We then tested for the positive selection of trait shifts of LAEWC under three scenarios: (1) positive selection on independent gain events of LAEWC, (2) positive selection on independent loss events of LAEWC, and (3) positive selection on an early gain event of LAEWC and a following loss event (Fig. 1a-c). The branch model under the codeml analysis of PAML v.4 [55] was used for hypotheses testing and the $K a / K s(\omega)>1$ was taken as the signature of positive selection. The model of constant evolutionary rate constraint on $\omega<1$ around all

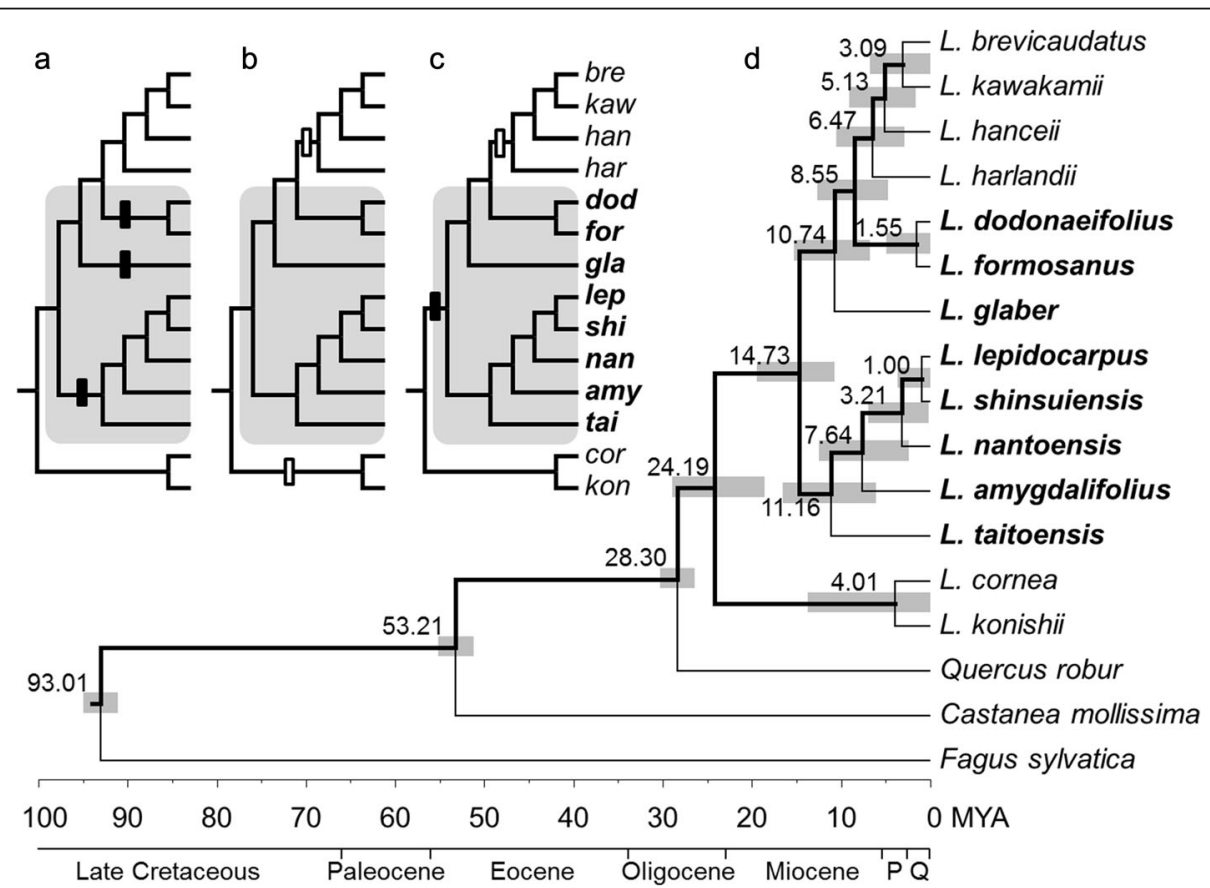

Fig. 1 Species tree and hypotheses of positive selection on LAEWC trait-shift events. Three positive selection hypotheses are: (a) positive selection independently acted on lineages that gained LAEWC, (b) positive selection independently acted on lineages of lost LAEWC, and (c) positive selection acted on the ancestor of all LAEWC lineages and secondarily acted on the branch of loss LAEWC. The gray area indicates the species with LAEWC. The solid bars and hollow bars indicate the gain events and loss events of LAEWC, respectively. (d) The species tree of the studied Lithocarpus species reconstructed using six LAEWC unrelated genes. Bold branches indicate $>95 \%$ posterior probability supporting values for grouping. Species with LAEWC were marked in bold, which revealed non-monophyletic relationship of either LAEWC species or non-LAEWC species. Values near the nodes are the estimated splitting time (Mya) with $95 \%$ highest posterior density (gray bars). P and $\mathrm{Q}$ at the geological time scale axis are Pliocene and Quaternary, respectively 
branches of the tree was used as the null hypothesis (Fig. 1). Likelihood ratio test (LRT), which calculates the $2 \times$ differences of log likelihood between null and alternative hypotheses $(2 \Delta \mathrm{L})$, was used for evaluating the best fit selective hypothesis by $\chi^{2}$ test.

\section{Ecophysiological measurements and analyses}

The presence or absence of LAEWC was suggested to be related to photosynthetic efficiency and water use efficiency (WUE = net photosynthetic rate/transpiration rate) [56, 57], carbon storage efficiency [57], and insect and pathogenic stress defenses [58-60], etc. Therefore, several environmental and ecophysiological parameters were measured for correlation with the LAEWC trait. However, as the experiments were all confined to plants growing in the Fushan Botanical Gardens and not in their original habitats, not all environmental factors could be directly measured or taken into account. In addition, WUE related characters such as stomata morphology of this genus have been reported in previous studies not to vary significantly between species [42, 43]. First, we measured the phytochemical yield of photosystem II (YII), which is an indication of energy used in photochemistry by photosystem II under steady-state photosynthetic lighting conditions, i.e. as an index of photosynthetic efficiency. More than 20 samples per species $(n=20 \sim$ 52) were measured for YII and three measurements of every leaf sample were averaged. YII was measured using MINI-PAM-II Photosynthesis Yield Analyzer (Heinz Walz GmbH, Germany).

Phenolic acids (PA) are a group of secondary metabolites related to pigmentation, growth, reproduction, resistance to pathogens and herbivores, etc. and represent adaptive characters that have been subjected to natural selection [61]. The PA are also thought to serve a chemical ecological role in plant resistance to fungal pathogens and phytophagous insects [61]. Dried leaves $(0.1 \mathrm{~g})$ were placed in a $60 \%$ methanol solution (contain $3 \% \mathrm{HCl}$ ), and then subjected to centrifugation for $10 \mathrm{~min}$ at $4{ }^{\circ} \mathrm{C}$ (3000 rpm). Total phenolic content was determined with the Folin-Ciocalteu reagent according to a procedure described by Singleton and Rossi [62] Briefly, $100 \mu \mathrm{L}$ of the sample was mixed with $2 \mathrm{~mL} 2 \%$ $(w / v)$ sodium carbonate solution for $2 \mathrm{~min}$, and then $2 \mathrm{~mL}$ of $50 \%$ Folin-Ciocalteu reagent was added into the reaction mixture. The absorbance readings were taken at $750 \mathrm{~nm}$ after incubation at room temperature for $30 \mathrm{~min}$. Gallic acid was used as a reference standard, and the results were expressed as milligram gallic acid equivalent (mg GAE)/g dry weight of herbal material. All species were measured four to five times and any outliers in the data discarded.
Carbon content $(\mathrm{C})$ is attributed to the lignin, cellulose, and carbohydrates [63], and is positively associated with environmental light conditions and negatively correlated with insect herbivore abundance [64]. Leaf nitrogen content $(\mathrm{N})$ is an integral component of protein RuBisCO and tends to correlate with the maximum photosynthetic rate [65] and is positively related to growth rates and energy supply [66]. The leaf $\mathrm{C} / \mathrm{N}$ ratio is a proxy of nutrient limitation (cf. [67-69]) and usually correlates with the potential growth rate (cf. [69]). In addition to the leaf $C$ and $\mathrm{N}$ content, we also measured the isotopic signature of leaf materials using the ratios of stable isotopes (R) of ${ }^{13} \mathrm{C} /{ }^{12} \mathrm{C}$ and ${ }^{15} \mathrm{~N} /{ }^{14} \mathrm{~N}$ and calculated the delta $(\delta)$ notation by the equation $\delta=\left[\left(R_{\mathrm{samp}} / R_{\mathrm{std}}\right)-1\right] \times 1000 \%$, where the $R_{\text {samp }}$ and $R_{\text {std }}$ are the isotopic ratios of samples and international standards (Vienna Pee Dee Belemnite for $\delta^{13} \mathrm{C}$ and air $\mathrm{N}_{2}$ for $\delta^{15} \mathrm{~N}$ ), respectively. Since during the carbon fixation process of photosynthesis, the RuBisCO can more easily utilize the ${ }^{12} \mathrm{CO}_{2}$ that may cause a lower concentration of ${ }^{13} \mathrm{C}$ than the atmospheric ${ }^{13} \mathrm{C}$, the $\delta^{13} \mathrm{C}$ can accurately reflect the carbon fixation $\left(\mathrm{CO}_{2}\right.$ uptake) efficiency of photosynthesis; similarly, the $\delta^{15} \mathrm{~N}$ can also more accurately reflect the reaction efficiency of RuBisCO than leaf $\mathrm{N}$ content [70]. The $\delta^{15} \mathrm{~N}$ is also suggested as an integrating parameter conditioning plant responsiveness (e.g., photosynthesis and water transpiration) to environments. For measuring the $\mathrm{C}, \mathrm{N}, \delta^{13} \mathrm{C}$, and $\delta^{15} \mathrm{~N}$, leaf samples $(n>5$ per species) were completely dried (oven-dried at $50^{\circ}$ $\mathrm{C}>7$ days) and ground into powders and mixed thoroughly. Dried powder samples were sent to SGS Taiwan Ltd. for measuring the $\mathrm{C}, \mathrm{N}, \delta^{13} \mathrm{C}$, and $\delta^{15} \mathrm{~N}$ following the protocol of Carter and Barwick [71].

Logistic regression was performed using the generalized linear model for testing the correlation of the ecophysiological traits with the presence/absence of LAEWC. LRT was used for comparing the null model. Phylogenetic principal component analysis (pPCA) [72] was conducted using all of the ecophysiological measurements and the altitudinal factors (the lowest (min Alt), highest (max Alt), middle altitudinal distributions (mid Alt), and the altitudinal range of distribution $(\Delta$ Alt $)$ ), with implementation of the $R$ packages phytools [73]. We further tested whether these traits were synchronously co-adapted with the LAEWC related genes by PS tests. Pagel's $\lambda[74]$ and Blomberg's $K$ [75], which operate under the assumption of Brownian motion of trait evolution [76], were used for testing the significance of phylogenetic correlation with traits. These analyses were based on the species tree and four gene trees of the LAEWC related genes. If the ecophysiological trait revealed significant PS with the species tree, the trait was suggested to fit the phylogenetic niche conservatism hypothesis (PNC, if $K>1$ [77]), or the character evolution fits a randomization process and is 
unrelated to the species evolution [77, 78]. If significant PS was detected with the gene tree, the trait was suggested to be coadapted with this gene.

\section{Results}

The SEM observation and differential LAEWC trait between species of Lithocarpus

In all examined Lithocarpus species, the stomata are presented on the abaxial surface only with no infraspecies variations (Fig. 2). According to the SEM observation, eight species have LAEWC, including L. amygdalifolius, L. dodonaeifolius, L. formosanus, L. glaber, L. lepidocarpus, L. nantoensis, L. shinsuiensis, and L. taitoensis (Fig. 2). The LAEWC are mostly thin film and flaky (Fig. 2). The leaf abaxial trichomes were observed accompanying the presence of the LAEWC (Fig. 2). In contrast, the other six species (L. brevicaudatus, L. cornea, L. hanceii, L. harlandii, L. kawakamii, and L. konishii, Fig. 2) lack LAEWC and show very few and sparse trichomes, presenting a glabrous and stomata-naked surface. The adaxial surfaces of all six examined were glabrous and lacked epicuticular wax crystals (Additional file 1: Figure S1). To ensure that the presence/absence of LAEWC is not plasticity and environmental influences, we also check consistency between our results and specimens from previous study [42]. All species adopted in both our study and previous study show consistency in presence/ absence in LAEWC, and revealed strong stability in presence/absence in LAEWC.

In general, five types of abaxial leaf surface were classified: (i) solitary unicellular trichomes growing through
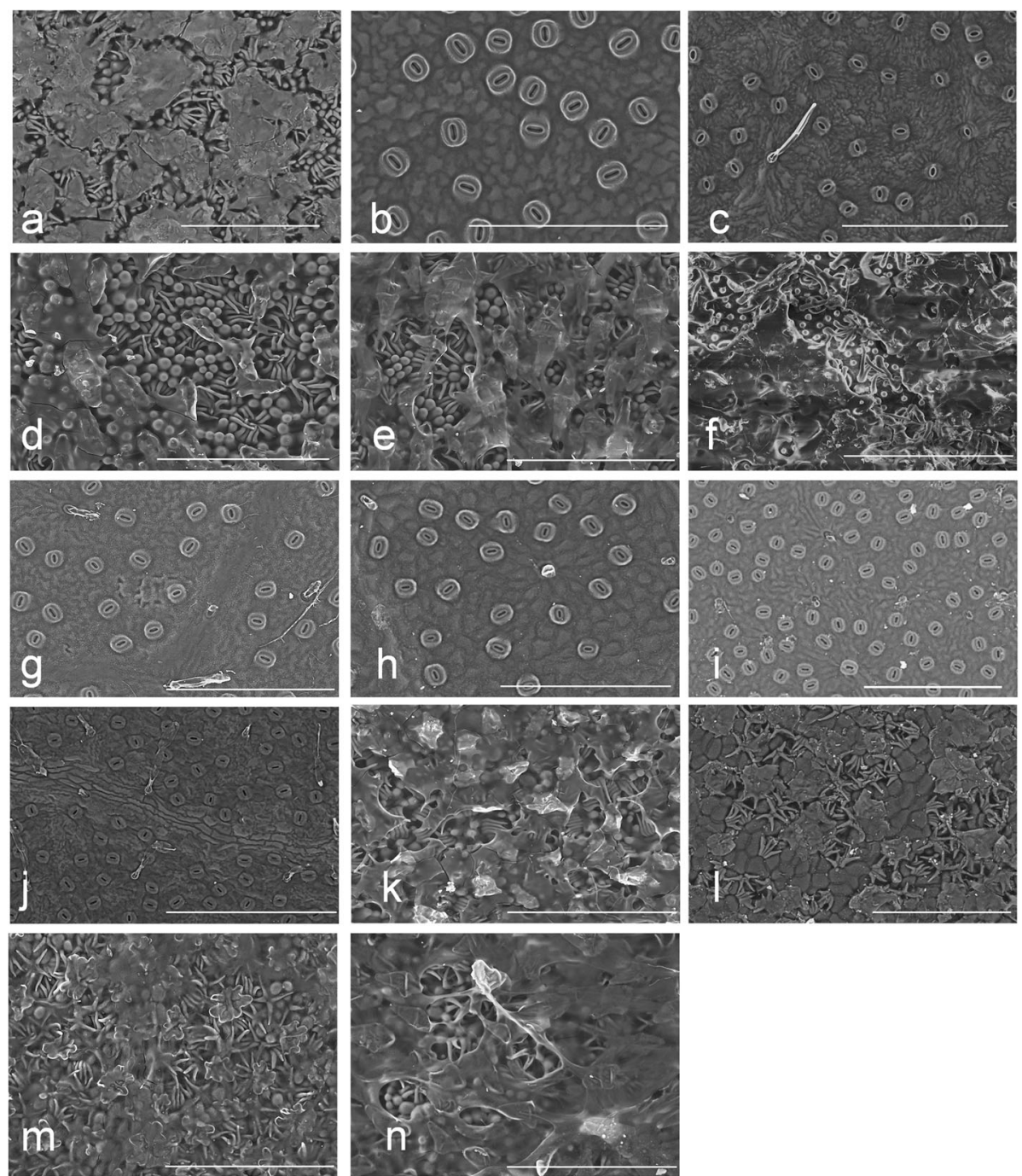

Fig. 2 Details of the abaxial layer of leaf epidermis of species of the genus Lithocarpus using Scanning Electron Microscope (SEM). a L. amygdalifolius; (b) L. brevicaudatus; (c) L. cornea; (d) L. dodonaeifolius; (e) L. formosanus; (f) L. glaber; (g) L. hanceii; (h) L. harlandii; (i) L. kawakamii; (j) L. konishii; (k) L. lepidocarpus; (I) L. nantoensis; (m) L. shinsuiensis; (n) L. taitoensis. The scale bar represents $200 \mu \mathrm{m}$ 
wax and stellate trichomes in the crack of the film-shaped wax crystals (Fig. 2a, d, m, n); (ii) almost full coverage of film-shaped wax crystals in the leaf abaxial surface (Fig. 2e); (iii) dense of solitary unicellular trichomes growing through pieces of wax crystals (Fig. 2f); (iv) solitary unicellular trichomes growing through pieces of wax films with uncovered stellate trichomes (Fig. 2k, l); (v) the naked stomata and no wax crystals covering the leaf abaxial surface (Fig. 2b, $c, g, h, i, j)$. In addition, leaf abaxial trichomes that coexist with the LAEWC vary between species: the parallel tuft trichome (Fig. 2d), stellate trichomes with papillae (Fig. 2a, d, e, k, n), solitary unicellular trichome (Fig. 2f), and broad base trichomes (Fig. 2c and j). Appressed parallel tufts were also present in eight species with LAEWC (Fig. 2a, d, e, f, k, n). Some species are glabrous on the leaf abaxial surface (Fig. 2b, c, $\mathrm{g}, \mathrm{h}, \mathrm{i}, \mathrm{j})$. The pattern of anticlinal walls and the shape of the epidermal cells are the main characteristics of the adaxial epidermis. Anticlinal walls are curved, straight, or sinuate. Epidermal cells are irregularly rounded, regular, or polygonal. No stomata were found on the adaxial surface (Additional file 1: Figure S1). The variety of trichomes between species are not the topic of this study but merit further investigation.

\section{The character state of LAEWC is not related to the spatial distribution}

According to species distribution modeling conducted by Maxent [79], with implementation of the $R$ packages dismo [80], several species have overlapping distributions and these distributions are not obviously different between species with LAEWC and without LAEWC (Additional file 1: Figure S2). This result suggests the presence/absence of LAEWC is not related to the current distribution of species or may not reflect fine-scale environmental differences within a small island.

\section{Phylogenetic analyses does not support a single trait-shift event of LAEWC}

The species tree revealed that species with LAEWC do not form a single clade; nor do species without LAEWC (Fig. 1d). A species tree reconstructed with six reference genes showed an ancestry for the studied Lithocarpus species dating to 24.19 Mya (Fig. 1d). Three independent lineages (clades) of species with LAEWC could be coalesced since 11.16 Mya, 10.74 Mya, and 1.55 Mya, and branches of non-LAEWC species could be coalesced to 6.47 Mya and 4.01 Mya (Fig. 1d). These dates are roughly in line with the late Miocene and Pliocene, which is older than the formation of Taiwan Island (less than 4 Mya) where the studied species are distributed [81-83]. Such dating indicates that the occurrence of these species in Taiwan was not a consequence of radiation after colonizing Taiwan Island but could point to multiple colonizing events. This inference was also supported by the chloroplast DNA tree with more taxa (Additional file 1: Figure S3). This result implies that the presence/absence of LAEWC was not the derived character for adapting to the island environment but could be a relict of an adaptive trait. The ancestor state (presence or absence) of LAEWC of Lithocarpus remains unknown because the phylogenetically closed genera (outgroups, Quercus and Castanea) have varied character states in LAEWC and ambiguous ancestral states inferred by MCMC simulation under the equal-rate (ER) model according to the chloroplast DNA tree (Additional file 1: Figure S3). Nevertheless, the phylogenetic analysis still provides evidence that the presence or absence of LAEWC is not a single event in Lithocarpus evolution (Fig. 1 and Additional file 1: Figure S3). Therefore, at least three evolutionary scenarios of gain or loss of LAEWC could be hypothesized: (a) gaining LAEWC are independent events, (b) losing LAEWC are independent events, and (c) losing LAEWC is a reversal event (Fig. 1a-c).

\section{Incongruent tree topologies between gene trees and} species tree inferred from reference genes

Generally, the grouping pattern of species with LAEWC and without LAEWC in the gene trees of CER1, CER3, and CER5 are similar to that of the species tree reconstructed from six reference genes, except that the haplotypes of $L$. harilandii (species without LAEWC) was grouped with $L$. dodonaeifolius (with LAEWC) (Fig. 3a-c). Certain species possess two haplotypes of the wax related genes and two haplotypes do not form a single clade, which was likely to be caused by gene duplication or retention of ancestral polymorphism [84]. According to previously reported in model species, only one copy can be found in all of the CER candidate genes from all model species [10, 14, 85, 86]. Besides, most species do not possess more than one haplotype. Therefore, different haplotypes within the species were regarded as intraspecific polymorphism rather than different members of a small gene family caused by duplication. In addition, within the LAEWC group, which did not form a monophyly in either gene tree or species tree, the L. taitoensis grouped with $L$. dodonaeifolius, L. formosanus, and L. glaber in gene trees of CER1, CER3, and CER5 (Fig. 3a-c), but grouped with $L$. lepidocarpus, $L$. nantoensis, $L$. shinsuiensis, and L. amygdalifolius in the species tree (Fig. 1). The gene tree of CER7 is different from the other gene trees and the species tree, which revealed a mosaic topological distribution of LAEWC species with non-LAEWC species (Fig. 3d). Furthermore, all clones of CER7 are 


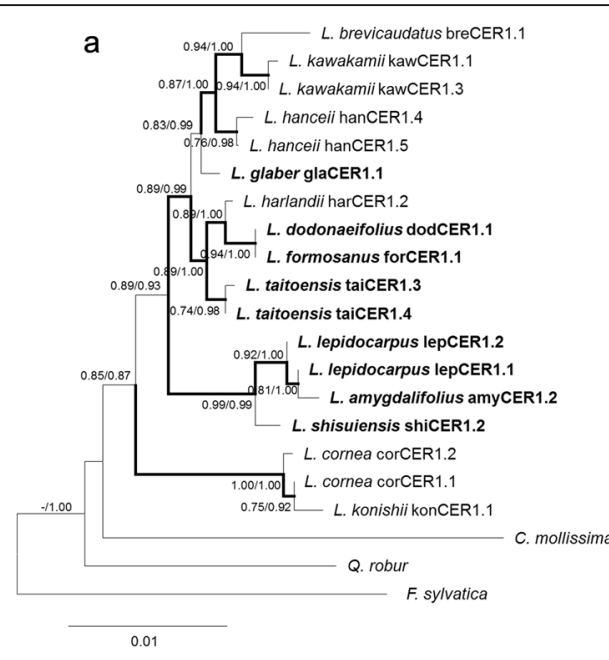

C

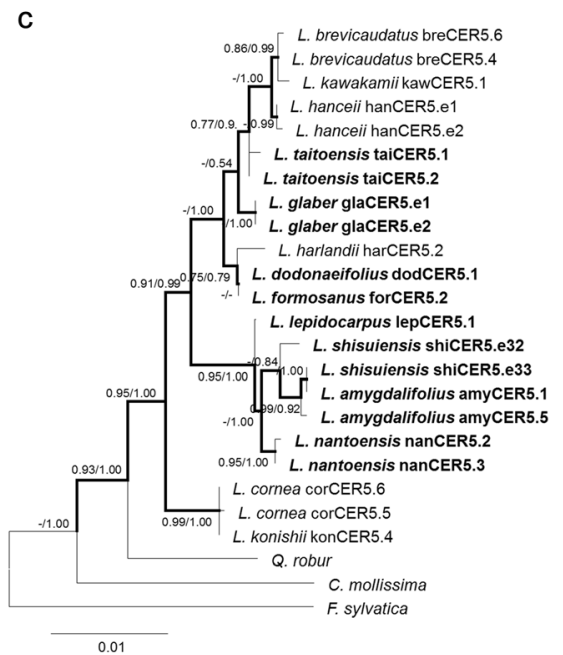

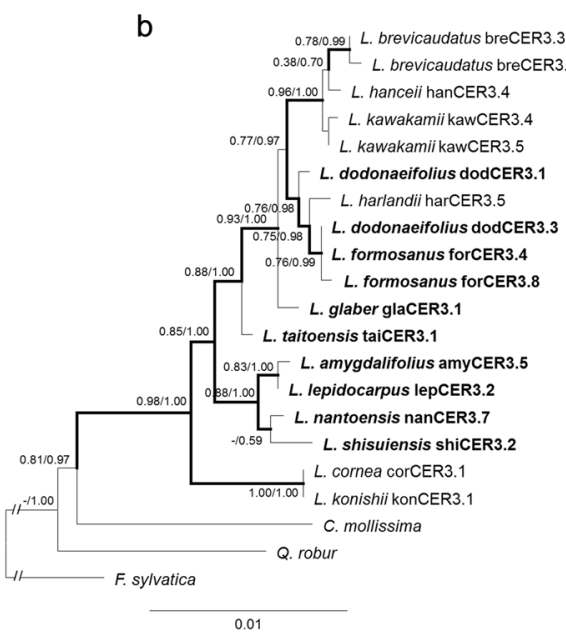

d

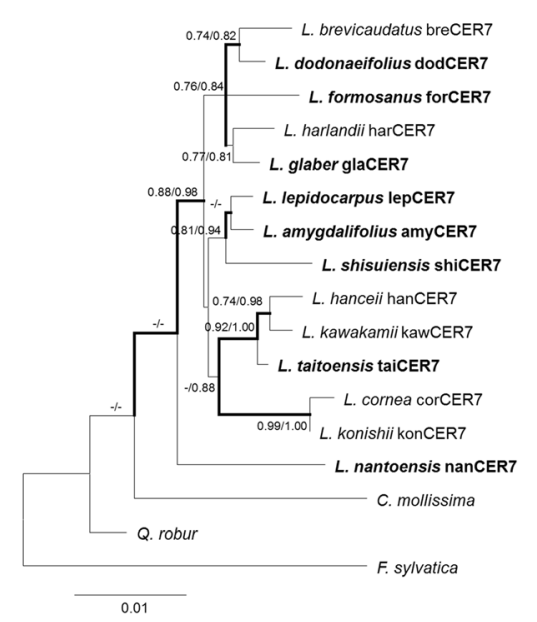

Fig. 3 Gene trees of LAEWC related genes (a) CER1, (b) CER3, (c) CER5, and (d) CER7. Tree topologies shown here are based on the neighborjoining method and the branches with bold indicate bootstrap values $>50 \%$ for supporting the deriving groups. Values of the nodes indicate the posterior probabilities of the supporting values inferred by the maximum likelihood (ML) and Bayesian inference (BI) methods (ML/BI). Dashes indicate the posterior probability $<50 \%$. The operational taxonomic units labeled in bold are the species with LAEWC. Codes after the species name are the haplotypes cloned in this study

monomorphic within species (one haplotype per species), revealing strong genetic constraint of species.

\section{Comparison of evolutionary rates of LAEWC related and unrelated genes}

The null hypothesis of WSRT is that there is no difference in the median between pairs of observations, while the null hypothesis of SLR implies independent distribution (no relationships) between two sets of observations. Hence, we use WSRT to test the difference in evolutionary rates between LAEWC related and unrelated genes and the rate of functional and unfunctional change of LAEWC related genes. We also conducted the SLR to test whether the LAEWC related genes evolve independently of species divergence or not. The Wilcoxon test shows significant differences in $K$ between LAEWC unrelated (reference) genes and CER3 $\left(P<2.2 \times 10^{-16}\right)$, CER5 $\left(P=1.13 \times 10^{-6}\right)$, and CER7 $(P=0.0005)$, but non-significant difference between reference genes and CER1 $(P=0.734)$ (Additional file 1: Figure S4A-D), which indicates that the evolutionary rate of $C E R 1$ does not differ from that of reference genes. Since most regions of the reference genes are non-coding regions (introns), which were suggested to be free of selection, we compared the $K$ of reference genes with the nonsynonymous substitution rate $(K s)$ of LAEWC related genes. Significant WSRT results $(P<0.05$ in all comparisons $)$ suggested different rates between the LAEWC related genes and reference genes, but the positive significance of the SLR suggests that the silent mutations of these LAEWC related genes still follow the sequence of 
species divergence (Additional file 1: Figure S4E-H). When comparing the $K s$ of LAEWC related genes to the nonsynonymous substitution rate $(K a)$, very significant lower $K a$ for these LAEWC related genes than $K s$ was found by WSRT (Additional file 1: Figure S4I-L). Taken together with the comparisons of $K s$ of LAEWC related genes and the $K$ of reference genes and the $K a$ vs. $K s$ of the LAEWC related genes, we concluded that these LAEWC related genes evolve more rapidly than other wax unrelated genes while experiencing strong selective pressure to constrain amino acid changes.

\section{Hypothesis testing indicates positive selection of CER1 on the gain events of LAEWC}

The results show that, except in the CER1 scenario of gaining LAEWC (hypothesis 1, Fig. 1a; $2 \Delta \mathrm{L}=6.754, P$ $=0.009$, Table 1$)$, the constant-rate model (M0) cannot be rejected in other LAEWC-related genes under all evolutionary scenarios of trait-shift events. Although three branches that inferred gaining LAEWC have an estimate of $\omega>1$ in CER1 under hypothesis 1 , not all branches were detected as having the same amino-acid replacement: only one and two amino acid replacements were found in L. glaber and in the branch of the common ancestor of $L$. dodonaeifolius and L. formosanus, respectively. No replacement was found in the common ancestor of other LAEWC species, implying a false positive. The gain of LAEWC in the early stages of the evolution of Lithocarpus was suggested to take place at multiple times and

Table 1 Results of likelihood ratio test of hypotheses of positive selection on LAEWC trait shift. The result shows that most LAEWC related genes were not positively selected during the trait shift of LAEWC except the CER1 under the hypothesis 1 (positive selection independently acted on the gain of LAEWC)

\begin{tabular}{lllllll}
\hline Hypothesis $^{\mathrm{a}}$ & Gene & $\ln L_{0}^{\mathrm{b}}$ & $\ln L_{A}^{\mathrm{b}}$ & $2 \Delta L$ & $\mathrm{df}$ & $P$ \\
\hline Hypothesis 1 $^{\mathrm{C}}$ & CER1 & -2969.327 & -2965.950 & 6.754 & 1 & 0.009 \\
& CER3 & -2923.209 & -2923.041 & 0.338 & 1 & 0.561 \\
& CER5 & -3516.913 & -3516.577 & 0.670 & 1 & 0.413 \\
& CER7 & -2009.028 & -2008.247 & 1.561 & 1 & 0.211 \\
Hypothesis 2 & CER1 & -2969.327 & -2969.322 & 0.010 & 1 & 0.919 \\
& CER3 & -2923.209 & -2923.133 & 0.153 & 1 & 0.696 \\
& CER5 & -3516.913 & -3516.908 & 0.010 & 1 & 0.921 \\
& CER7 & -2009.028 & -2007.660 & 2.735 & 1 & 0.098 \\
Hypothesis 3 & CER1 & -2969.327 & -2967.980 & 2.694 & 2 & 0.260 \\
& CER3 & -2923.209 & -2923.210 & 0 & 2 & $N A$ \\
& CER5 & -3516.913 & -3516.913 & 0 & 2 & 1 \\
& CER7 & -2009.028 & -2007.662 & 2.731 & 2 & 0.255 \\
\hline
\end{tabular}

${ }^{\mathrm{a}}$ Hypothesis 1: Fig. 1a; Hypothesis 2: Fig. 1b; Hypothesis 3: Fig. 1c

${ }^{b} \ln L_{0}$ : natural logarithm of the likelihood of null model; $\ln L_{A}$ : natural logarithm of the likelihood of alternative model independently from a probable ancestral state of absence of LAEWC (Additional file 1: Figure S3). However, certain lineages of LAEWC loss were inferred (Additional file 1: Figure S3), but none of these "loss" events were suggested to be under selective pressure (Table 1). We also tested whether positive selection acts on retaining LAEWC by allowing $\omega>1$ in all derived lineages after gaining or losing the LAEWC trait. The results show that the null hypothesis of constant-rate model cannot be rejected in all situations (Additional file 1: Table S2). This implies that the episodic gains of LAEWC may be responsible for adaptive radiation rather than lasting divergence.

\section{Association of PA with the evolution of LAEWC-related genes}

To understand whether the gain of LAEWC benefits the adaptation of trees, certain ecophysiological traits concerning photosynthesis or stress defense, etc. were measured (Additional file 1: Table S3) and used as independent variables to correlate with the character of LAEWC. Except the $\mathrm{C}$ and $\mathrm{C} / \mathrm{N}$ ratio $(2 \Delta \mathrm{L}=5.791$ and $3.845, P=0.016$ and 0.050 , respectively, Table 2 ), the empty model cannot be rejected by the models with other independent variables (Table 2). Even so, the effect of $\mathrm{C}$ and $\mathrm{C} / \mathrm{N}$ still fails to significantly predict the character state of LAEWC $(P=0.111$ and 0.090 , respectively, Table 2). These results suggest that the presence/absence of LAEWC does not covary with current ecophysiological traits, i.e. is unrelated to current environmental pressures. This result is consistent with the lack of covariance of LAEWC with other ecophysiological characters in phylogenetic principal component analysis (Fig. 4).

PS analyses showed that no ecophysiological variables reflect species evolution, but the PA can reflect the gene evolution of CER1 $(K=0.483, P=0.014)$ and

Table 2 Logistic regression of every ecophysiological trait with the presence or absence of LAEWC, which revealed non-significant correlation with LAEWC in all ecophysiological traits

\begin{tabular}{lllllll}
\hline Variable & Estimate & SE & $z$ value & $\operatorname{Pr}(>|z|)$ & $\log L$ & $L_{R T^{b}}$ \\
\hline Null $^{a}$ & - & - & - & - & -9.561 & - \\
YII & 14.740 & 14.780 & 0.997 & 0.319 & -9.018 & 0.297 \\
$\mathrm{PA}$ & 0.033 & 0.031 & 1.045 & 0.296 & -8.895 & 0.249 \\
$\delta^{13} \mathrm{C}$ & 0.665 & 0.748 & 0.889 & 0.374 & -9.130 & 0.354 \\
$\delta^{15} \mathrm{~N}$ & -1.412 & 1.072 & -1.317 & 0.188 & -8.174 & 0.096 \\
$\mathrm{C}$ & 94.100 & 58.980 & 1.595 & 0.111 & -6.665 & 0.016 \\
$\mathrm{~N}$ & -176.590 & 126.725 & -1.393 & 0.163 & -8.348 & 0.119 \\
$\mathrm{C} / \mathrm{N}$ & 0.171 & 0.101 & 1.697 & 0.090 & -7.638 & 0.050 \\
\hline
\end{tabular}

athe empty model

${ }^{b}$ the likelihood ratio test in which the model is compared with the empty model using $2 \times$ delta log likelihood $(2 \Delta \mathrm{L})$ 


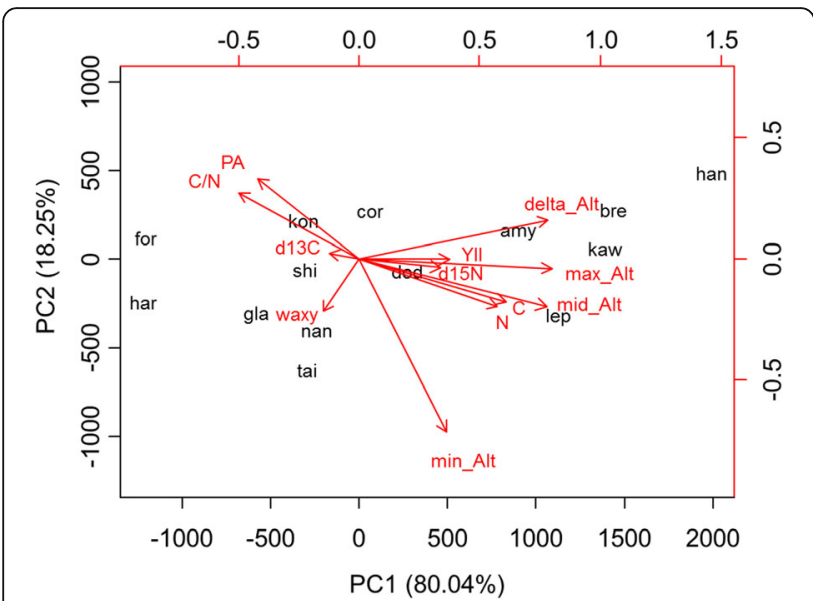

Fig. 4 Phylogenetic principal component analysis (PPCA) conducted with the reference tree. Black wording indicates abbreviation of each species (see Fig. 1), while the red wording indicates ecophysiological traits. (C:carbon content; N: nitrogen content; PA: phenolic acid; C/N: ratio of carbon and nitrogen content; d13C: $\delta^{13} \mathrm{C} ; \mathrm{d} 15 \mathrm{~N}: \delta^{15} \mathrm{~N}$; waxy: LAEWC state; Alt: altitude; Yll: phytochemical yield of photosystem II)

CER3 $\quad(\lambda=0.870, \quad P=0.011 ; \quad K=0.549, \quad P=0.007$, Table 3). Significant PS of PA in the CER1 and CER3 gene trees suggest coevolution of the PA and LAEWC backbone genes. However, the hypothesis of phylogenetic conservatism in both chemical (PA) and physical (LAEWC) stress defense is rejected due to the $K<1$. In addition to the $\mathrm{PA}$, the $\mathrm{C} / \mathrm{N}$ ratio that represents the potential growth rate and nutrient limitation may also reflect the evolution of CER5 gene (Blomberg's $K$ $=0.290, P=0.034$, Table 3 ). However, nonsignificant PS detected in $\mathrm{C}, \mathrm{N}, \delta^{13} \mathrm{C}$, and $\delta^{15} \mathrm{~N}$, and YII in the CER5 gene tree and other gene trees (Table 3) indicate no relationship between the adaptive evolution of LAEWC and photosynthesis efficiency, water usage efficiency, and/or nutrient allocations.

\section{Discussion}

\section{Synchronous character states in the LAEWC} and trichomes

This study used 14 Lithocarpus species distributed on Taiwan Island to investigate the adaptive character of LAEWC by means of genetic and ecophysiological assessments. First, the SEM showed that eight of 14 species have an obvious film-shaped wax crystal structure on the leaf surface abaxial layer (Fig. 2) but only very sparse, or sometimes no, wax films were found on the leaf adaxial layer (Additional file 1: Figure S1). Lack of leaf adaxial wax crystals suggest no selective pressure or pressure of light intensity on the evolutionary shaping of leaf epicuticular wax in Lithocarpus (cf. [87]). In contrast, the differences in film-shaped wax crystals on the abaxial layer, where the stomata are mainly distributed, suggest the ecophysiological relevance of LAEWC in photosynthesis efficiency and/or water conservation. A study of grasses (Agrosti stolonifera, Poaceae) further indicated that the difference in distribution of the extracellular wax on leaf surfaces can also be related to the retention of salt at different localities [88]. Interestingly, the presence of trichomes was associated with the presence of LAEWC in our study materials (Fig. 2) and the diverse forms of trichome have also been reported and discussed in previous study [42, 43], although it should be noted that few exceptions have been reported in species which were not adopted in our study (e.g, $L$. calophyllus and L. oleifolius in [42]). Co-occurrence of these traits may suggest, for example, that synergistic functions for adaptation play the role of physical barrier in the defense against insect biting [87] or water repellency [89]. However, the trichome types are more complicated than the wax films in Lithocarpus (Fig. 2). Hence the trichomes' ecophysiological functions, their potential linkage with wax films, the linkage of trichome morphogenesis related gene such as MIXTA-like [90], and adaptive characters are not discussed here.

Table 3 Phylogenetic signals of ecophysiological traits with species tree and four LAEWC-related-gene trees

\begin{tabular}{lllllllll}
\hline & Test & YII & PA & $\delta^{13} \mathrm{C}$ & $\delta^{15} \mathrm{~N}$ & $\mathrm{C}$ & $\mathrm{N}$ \\
\hline Species tree & Pagel's $\lambda$ & $6.90 \mathrm{E}-05$ & 0.637 & $6.90 \mathrm{E}-05$ & 0.363 & $6.90 \mathrm{E}-05$ & $6.90 \mathrm{E}-05$ & $6.90 \mathrm{E}-05$ \\
& Blomberg's K & 0.267 & 0.326 & 0.445 & 0.458 & 0.241 & 0.170 & 0.184 \\
CER1 gene tree & Pagel's $\lambda$ & 0.567 & 0.640 & $6.70 \mathrm{E}-05$ & 0.527 & $4.25 \mathrm{E}-05$ & $6.70 \mathrm{E}-05$ & $7.55 \mathrm{E}-05$ \\
& Blomberg's K & 0.164 & $0.483^{*}$ & 0.353 & 0.355 & 0.096 & 0.150 & 0.141 \\
CER3 gene tree & Pagel's $\lambda$ & $6.79 \mathrm{E}-05$ & $0.870^{*}$ & $6.79 \mathrm{E}-05$ & 0.612 & $6.79 \mathrm{E}-05$ & $6.79 \mathrm{E}-05$ & $6.79 \mathrm{E}-05$ \\
& Blomberg's K & 0.201 & $0.549^{*}$ & 0.205 & 0.254 & 0.161 & 0.173 & 0.204 \\
CER5 gene tree & Pagel's $\lambda$ & $6.72 \mathrm{E}-05$ & 0.453 & 0.077 & 0.519 & $6.72 \mathrm{E}-05$ & $6.72 \mathrm{E}-05$ & $6.72 \mathrm{E}-05$ \\
& Blomberg's K & 0.211 & 0.088 & 0.206 & 0.196 & 0.074 & 0.209 & $0.290^{*}$ \\
CER7 gene tree & Pagel's $\lambda$ & $6.90 \mathrm{E}-05$ & 0.637 & $6.90 \mathrm{E}-05$ & 0.363 & $6.90 \mathrm{E}-05$ & $6.90 \mathrm{E}-05$ & $6.90 \mathrm{E}-05$ \\
& Blomberg's K & 0.267 & 0.326 & 0.445 & 0.458 & 0.241 & 0.170
\end{tabular}




\section{Functional independency of LAEWC to all ecophysiological traits}

Most of the factors we measured do not reveal significant PS of the species tree, including photosynthesis efficiency, water usage efficiency, and/or nutrient allocation dependent characters. This is consistent with other leaf abaxial characters - for example, there are no distinguishable differences in morphology/distribution of stomata, abaxial epidermal cell walls, and epidermal hairs $[42,53]$ - although we could not exclude other factors driving adaptation in Lithocarpus. Among these factors, the contents of PA revealed significant PS with the gene trees of the backbone genes of the wax biosynthesis pathway (i.e. CER1 and CER3, Table 3). The makeup of defensive chemicals usually directly reflects the herbivore stress of plants and reveals strong signs of positive selection [91, 92]. Cuticular or epicuticular waxes of the leaf surface are suggested to play a role in physical defense $[60,87]$. Two hypotheses could explain the coevolutionary relationship between the chemical and physical defensive strategies: (1) the trade-off between the chemical and physical defensive investment that causes negative results of correlation [30-32], and (2) synergistic defense hypothesis suggests a positive correlation between chemical and physical trait values [33]. Similarly, the trade-off between the defensive and growth investments in plants could result in negative correlations between the defensive and photosynthesis (or nutrient) trait values. However, our study shows neither a positive nor a negative correlation between chemical and physical defensive traits, as well as no correlation between LAEWC and photosynthesis or nutrient uptake/storage indices (Table 2). This means that the trade-off hypothesis for the resource investment of chemical and physical defensive strategies is not supported. Our result is similar to that found in myrmecophilic plant Macaranga tanarius which showed that the chemical composition of the leaf revealed no correlation with the wax contents of the leaf surfaces [93]. However, in that case, a strong positive correlation with the density of trichomes was detected, suggesting complicated synergistic defensive strategies of plants [93]. This study echoes the above and considers trichomes worthy of future exploration. At the same time, the phylogenetic PCA revealed the opposite explanatory dimensions on the chemical defensive trait (PA) and other nutrient and photosynthesis indices (Fig. 4), showing support for the trade-off hypothesis between defensive and growth investment in Lithocarpus. Evidence in support of another hypothesis, that spreading the risks of resource investment resulted in general phenomenon of less or no association between defensive traits, i.e. independently evolving, was not uncovered [33].

\section{Evolutionary change of LAEWC co-adapts with the PA}

Though we failed to find correlations between any ecophysiological trait and LAEWC (Table 2), our study has found evidence for a strong relationship between PA content and the evolution of backbone genes of the wax biosynthesis pathway. One of the backbone genes, CER1, was also found to be positively associated with gaining of LAEWC (Table 1), suggesting a synchronization of the relationship between the evolution of chemical and physical defensive traits. Although other potential functional interpretations could be considered in CER1 - for example, pollen morphogenesis [15] and adaxial wax cuticle [16] - the possibility of adaptive interpretation in pollen or adaxial wax cuticle seems to be unlikely due to very little variation in pollen [94] and adaxial cuticle morphology $[53,54]$. Therefore, we focus our discussion on defensive traits with LAEWC and CER1. Contrasting hypotheses of parallel evolution and coadaptation explain how the chemical (e.g. PA) and physical (e.g. LAEWC) defensive characters covary: the former describes synergistic evolution of both traits following species divergence, while the latter suggests synchronous changes of characters in response to the same stress but independent from the evolution sequence of the species. In this case, nonsignificant PS of the PA with the species tree has excluded the possibility of parallel evolution of these two traits. Several studies have shown independent or unlinked relationships between the chemical and physical defensive traits and do not support the parallel evolution hypothesis of two defensive strategies [42, 87, 93].

In contrast, a coadaptive evolutionary relationship in both PA and LAEWC was suggested due to significant PS of PA on the backbone genes of wax biosynthesis (Table 3). In addition, the positive selection on the CER1 gene at the time of gaining LAEWC implies that the association of PA with the evolution of wax backbone genes reflects the adaptive consequence of character innovation. Besides CER1, none of the examined genes have signs of positive selection in any possible evolutionary scenarios (Table 1). Positive selection on backbone gene CER1 suggests that the trait shift of LAEWC is the overriding functional change for adaption. Overexpression of CERlinduced by osmotic stresses will increase the production and accumulation of the raw materials of cuticle wax, which was shown to increase plant susceptibility to bacterial and fungal pathogens as well as reduce cuticle permeability and soil-water deficit susceptibility in Arabidopsis [10].

Although the state of LAEWC in the common ancestor of the extant Lithocarpus is ambiguous, the gaining of LAEWC likely happened in the early stages of species divergence (Additional file 1: Figure S3). This idea is supported by the absence of LAEWC in the sister group, Chrysolepis, after observation by SEM [54]. The positive selection detected upon the of gaining of LAEWC indicates adaptive advantages of LAEWC in Lithocarpus. 
Furthermore, the selective pressure on CER1 was not retained for maintaining the character (Additional file 1: Table S2). Functional traits of leaves such as the specific leaf area and hydraulic traits were suggested to be associated with the species niche and strongly reflect species distribution [95, 96]. However, modeling for species distribution based on current climate variables indicated no obvious differences between the species with and without LAEWC (Additional file 1: Figure S2). This may suggest that the trait of LAEWC may reflect past environmental change which led to trait shifts rather than current environmental realities.

\section{Late-Miocene-to-Pliocene climate change explains the trait-shift of LAEWC in Lithocarpus}

The timing of the trait transition of LAEWC was suggested as the late Miocene and Pliocene (Fig. 1). Late Miocene to Quaternary climate change may coincide with the trait shift events of LAEWC in Lithocarpus. The Miocene climate was slightly warmer and wetter and spawned the monsoon system which has affected Asian vegetation [97-99]. After the late Miocene, the climate gradually cooled and became arid [100, 101]. The late-Miocene-to-Pliocene climate change accelerated the diversification of insular species [102-105], which may be partly due to sea-level fluctuations accompanying disjunction and connection between continents and islands [106]. The synergy of genetic isolation and adaptation to the rugged topography may have accelerated the speciation process in southeastern Asian islands.

Trait innovation has been found to enhance the diversification of several plants since the late-Miocene-to-Pliocene boundary. For example, the appearance of winged seeds in Parrya and Diptychocarpus of Brassicaceae may aid in plant colonization [107]. As with Parrya and Diptychocarpus, acquiring the LAEWC to increase survival by defending against insects may have accelerated species diversification in these tropical and subtropical stone oaks in the late-Miocene-to-Pliocene period at the same time that insect species were diversifying, including tropical-forest beetles [108], most genera of Nymphalid [109], and fruit fly (Rhagoletis, [110]). In addition, some plant species developed higher drought adaptability usually characterized by water-conserving traits (i.e. high hydraulic safety margins) and, as with the presence of LAEWC in Lithocarpus, show a higher potential of resistance to climate change [95]. However, although these traits can reflect environmental and climate change, they may act somewhat independently of one another [14], hence these traits were poorly correlated with each other (Table 2) in our study. This may be because the specific combination of traits may maximize species performance only in specific environments [111].

\section{Conclusions}

The late-Miocene-to-Pliocene positive selection on backbone gene CER1 of leaf epicuticular wax accompanying the content of PA of chemical defensive traits suggests the adaptive change and diversification rate coincides with the diversification of many herbivorous insects and potential link between PA, wax, and defensive adaptation in Lithocarpus. The selective pressure which produced this linkage did not persist over time; however, the trait transition has remained. None correlation of the wax trait with the other ecophysiological characters suggests functional independency. The evolutionary association in chemical and physical defensive strategies was suggested as a coadaptive phenomenon to resist multiple or complicated phytophagous stress instead of reflecting the parallel evolution of traits. Our study began with a morphological observation and concluded having found evidence of the synchronous adaptive change of defensive traits under past selective pressure, uncovered through genetic and ecophysiological analyses. We contribute a possible explanation of the mechanism for the diversification of tropical and subtropical forest species in the face of climate change.

\section{Additional file}

\begin{abstract}
Additional file 1: Figure S1. Detail of adaxial layer of leaf epidermis of the genus Lithocarpus using Scanning Electron Microscope (SEM). (A) L. amygdalifolius; (B) L. brevicaudatus; (C) L. cornea; (D) L. dodonaeifolius; (E) L. formosanus; (F) L. glaber; (G) L. hanceii; (H) L. harlandii; (I) L. kawakamii; (J) L. konishii; (K) L. lepidocarpus; (L) L. nantoensis; (M) L. shinsuiensis; (N) L. taitoensisx. The SEM shows that no epicuticular wax crystals covered the leaf adaxial leaf surface in Lithocarpus. The scale bar represents $200 \mu \mathrm{m}$. Figure S2. The spatial distribution reconstructed according to the current sampling records from GBIF and predicted using a machine-learning algorithm, maximum entropy algorithms, implemented in Maxent [79]. Figure S3. Ancestral state inference of discrete characters using the Maximum likelihood framework assuming one-parameter equal rates (ER) of character transition model and summarizing the 300 simulated character reconstructions. Figure S4. Pairwise comparison of substitution rates ( $K$ ) of LAEWC related genes and reference genes using simple linear regression (SLR) and dependent two-group Wilcoxon Signed Rank Test (WSRT). Table S1. Primer list and annealing temperatures used in this study. Table S2. Results of likelihood ratio test of hypotheses of positive selection on retaining the gain or loss of LAEWC trait. Table S3. Ecophysiological measurements and altitudinal distribution of Lithocarpus species tested in this study. (PDF $1094 \mathrm{~kb}$ )
\end{abstract}

\footnotetext{
Abbreviations

$2 \Delta \mathrm{L}$ : $2 \times$ differences of log likelihoods between two models; ABC: ATPbinding cassette; ABCG: ABC transporter G family; aLRT: Approximate likelihood-ratio test; Alt: Altitude; BI: Bayesian inference; C: Carbon content; CER: ECERIFERUM; ER: Eequal rates; GAE: Gallic acid equivalent; K: Substitution rate of all nucleotides; Ka: Nonsynonymous substitution rate; Ks: Synonymous substitution rate; LAEWC: Leaf abaxial epicuticular wax crystals; LTER: Long-term ecological research; LTP: LIPID TRANSFER PROTEIN; MO: Constant-rate model; MCMC: Markov chain Monte Carlo; ML: Maximum-likelihood; Mya: Million years ago; N: Leaf nitrogen content; NJ: Neighbor-joining; NNI: Nearest neighbor interchange; PA: Phenolic acids; PNC: Phylogenetic niche conservatism; pPCA: Phylogenetic principal component analysis; PS: Phylogenetic signal; R: Stable isotope ratio; SEM: Scanning Electron Microscopy; SLR: Simple linear regression; VLCFAs: Very-long-chain-fatty-acids; WBC: White-brown complex
} 
homolog protein; WIN1: WAX INDUCER1; WSRT: Wilcoxon Signed Rank Test; WUE: Water use efficiency; Yll: Phytochemical yield of photosystem II; $\Delta$ Alt: Altitudinal range of distribution; $\omega: K a / K s$

\section{Acknowledgements}

The authors thank Shih-Ying Hwang, Yu-Chung Chiang, and Chun-Neng Wang for their suggestions to improve this study, and thank Dawn Schmidt and Dr. Rosemary Pennington for English editing. We thank the National Center for Genome Medicine of the National Core Facility Program for Biotechnology, Ministry of Science and Technology, for the technical/bioinformatics support.

\section{Funding}

This research was financially supported by the Ministry of Science and Technology in Taiwan (MOST 105-2628-B-003 -002 -MY3) and was also subsidized by the National Taiwan Normal University (NTNU), Taiwan.

\section{Availability of data and materials}

All sequences presented in this study were deposited in the NCBI GenBank under Accessions KY458808-KY458955.

\section{Authors' contributions}

PL and JW conceived this study. CY and SH collected materials. CY, BH, MH and SH conducted experiments. BH, JG and SH analysed the data. PL wrote the paper. JW, CY and BH critically reviewed the manuscript. All authors participated in the discussion and read and approved the final manuscript.

\section{Ethics approval and consent to participate}

Not applicable.

\section{Consent for publication}

Not applicable.

\section{Competing interests}

The authors declare that there are no conflicts of interest.

\section{Publisher's Note}

Springer Nature remains neutral with regard to jurisdictional claims in published maps and institutional affiliations.

\section{Author details}

'School of Life Science, National Taiwan Normal University, Postal address: No. 88, Tingchow Rd. Sect. 4, Taipei 11677, Taiwan. ${ }^{2}$ The Experimental Forest, College of Bio-Resources and Agriculture, National Taiwan University, Taipei, Nantou 55750, Taiwan. ${ }^{3}$ Department of Horticulture and Biotechnology, Chinese Culture University, Taipei 11119, Taiwan. ${ }^{4}$ Faculty of Resources and Environment, Baotou Teachers' College, Inner Mongolia University of Science and Technology, Inner Mongolia 014010, China.

Received: 6 November 2017 Accepted: 7 September 2018

\section{Published online: 17 September 2018}

\section{References}

1. Yeats TH, Rose JKC. The formation and function of plant cuticles. Plant Physiol. 2013;163(1):5-20.

2. Haworth M, McElwain J. Hot, dry, wet, cold or toxic? Revisiting the ecological significance of leaf and cuticular micromorphology. Palaeogeogr Palaeocl. 2008;262(1-2):79-90.

3. Hill RS. Fossil evidence for the onset of xeromorphy and scleromorphy in Australian Proteaceae. Aust Syst Bot. 1998;11(3-4):391-400.

4. Becker M, Kerstiens $G$, Schonherr J. Water permeability of plant cuticles: permeance, diffusion and partition coefficients. Trees-Struct Funct. 1986;1(1): 54-60.

5. Richardson A, Franke R, Kerstiens G, Jarvis M, Schreiber L, Fricke W. Cuticular wax deposition in growing barley (Hordeum vulgare) leaves commences in relation to the point of emergence of epidermal cells from the sheaths of older leaves. Planta. 2005;222(3):472-83.

6. Brewer CA, Smith WK. Leaf surface wetness and gas-exchange in the pond lily Nuphar polysepalum (Nymphaeaceae). Am J Bot. 1995;82(10):1271-7.

7. Bargel H, Barthlott W, Koch K, Schreiber L, Neinhuis C. Plant cuticles: multifunctional interfaces between plant and environment. In: Hemsley AR,
Poole I, editors. The Evolution of Plant Physiology. London: Linnean Society Symposium Series, Elsevier Academic Press; 2004. p. 171-94.

8. Serrano M, Coluccia F, Torres M, L'Haridon F, Metraux JP. The cuticle and plant defense to pathogens. Front Plant Sci. 2014;5:274.

9. Samuels L, Kunst L, Jetter R. Sealing plant surfaces: Cuticular wax formation by epidermal cells. Annu Rev Plant Biol. 2008;59:683-707.

10. Bourdenx B, Bernard A, Domergue F, Pascal S, Leger A, Roby D, Pervent M, Vile D, Haslam RP, Napier JA, et al. Overexpression of Arabidopsis ECERIFERUM1 promotes wax very-long-chain alkane biosynthesis and influences plant response to biotic and abiotic stresses. Plant Physiol. 2011; 156(1):29-45.

11. Kannangara R, Branigan C, Liu Y, Penfield T, Rao V, Mouille G, Hofte H, Pauly $M$, Riechmann JL, Broun P. The transcription factor WIN1/SHN1 regulates cutin biosynthesis in Arabidopsis thaliana. Plant Cell. 2007;19(4):1278-94.

12. Kosma DK, Bourdenx B, Bernard A, Parsons EP, Lu S, Joubes J, Jenks MA. The impact of water deficiency on leaf cuticle lipids of Arabidopsis. Plant Physiol. 2009;151(4):1918-29.

13. Koenig D, Jimenez-Gomez JM, Kimura S, Fulop D, Chitwood DH, Headland LR, Kumar R, Covington MF, Devisetty UK, Tat AV, et al. Comparative transcriptomics reveals patterns of selection in domesticated and wild tomato. P Natl Acad Sci USA. 2013;110(28):E2655-62.

14. Bernard A, Domergue F, Pascal S, Jetter R, Renne C, Faure JD, Haslam RP, Napier JA, Lessire R, Joubes J. Reconstitution of plant alkane biosynthesis in yeast demonstrates that Arabidopsis ECERIFERUM1 and ECERIFERUM3 are core components of a very-long-chain alkane synthesis complex. Plant Cell. 2012;24(7):3106-18.

15. Aarts MG, Keijzer CJ, Stiekema WJ, Pereira A. Molecular characterization of the CER1 gene of arabidopsis involved in epicuticular wax biosynthesis and pollen fertility. Plant Cell. 1995;7(12):2115-27.

16. Bourdenx B, Bernard A, Domergue F, Pascal S, Léger A, Roby D, Pervent M, Vile D, Haslam RP, Napier JA, et al. Overexpression of Arabidopsis CER1 promotes wax VLC-alkane biosynthesis and influences plant response to biotic and abiotic stresses. Plant Physiol. 2011;156(1):29-45.

17. Lam P, Zhao LF, McFarlane HE, Aiga M, Lam V, Hooker TS, Kunst L. RDR1 and SGS3, components of RNA-mediated gene silencing, are required for the regulation of Cuticular wax biosynthesis in developing inflorescence stems of Arabidopsis. Plant Physiol. 2012;159(4):1385-95.

18. MCFarlane HE, Shin JJH, Bird DA, Samuels AL. Arabidopsis ABCG transporters, which are required for export of diverse cuticular lipids, dimerize in different combinations. Plant Cell. 2010;22(9):3066-75.

19. Pighin JA, Zheng HQ, Balakshin LJ, Goodman IP, Western TL, Jetter R, Kunst L, Samuels AL. Plant cuticular lipid export requires an $A B C$ transporter Science. 2004;306(5696):702-4.

20. Dodd RS, Afzal-Rafii Z. Habitat-related adaptive properties of plant cuticular lipids. Evolution. 2000;54(4):1438-44.

21. Violle C, Navas ML, Vile D, Kazakou E, Fortunel C, Hummel I, Garnier E. Let the concept of trait be functional! Oikos. 2007:116(5):882-92.

22. Reich PB, Wright IJ, Cavender-Bares J, Craine JM, Oleksyn J, Westoby M, Walters MB. The evolution of plant functional variation: traits, spectra, and strategies. Int J Plant Sci. 2003;164(3):S143-64.

23. Diaz S, Kattge J, Cornelissen JHC, Wright IJ, Lavorel S, Dray S, Reu B, Kleyer M, Wirth C, Prentice IC, et al. The global spectrum of plant form and function. Nature. 2016:529(7585):167-71.

24. Reich PB. The world-wide 'fast-slow' plant economics spectrum: a traits manifesto. J Ecol. 2014;102(2):275-301.

25. Maire V, Gross N, Hill D, Martin R, Wirth C, Wright IJ, Soussana JF. Disentangling coordination among functional traits using an individualcentred model: impact on plant performance at intra- and inter-specific levels. PLoS One. 2013;8(10):e77372

26. Agrawal AA, Fishbein M. Plant defense syndromes. Ecology. 2006;87(7): S132-49.

27. Treutter D. Significance of flavonoids in plant resistance: a review. Environ Chem Lett. 2006;4(3):147-57.

28. Bonhomme V, Pelloux-Prayer H, Jousselin E, Forterre Y, Labat JJ, Gaume L. Slippery or sticky? Functional diversity in the trapping strategy of Nepenthes carnivorous plants. New Phytol. 2011;191(2):545-54.

29. Peguero-Pina JJ, Siso S, Fernandez-Marin B, Flexas J, Galmes J, GarciaPlazaola Jl, Niinemets U, Sancho-Knapik D, Gil-Pelegrin E. Leaf functional plasticity decreases the water consumption without further consequences for carbon uptake in Quercus coccifera L under Mediterranean conditions. Tree Physiol. 2016;36(3):356-67. 
30. Read J, Sanson GD, Caldwell E, Clissold FJ, Chatain A, Peeters P, Lamont BB, De Garine-Wichatitsky M, Jaffre T, Kerr S. Correlations between leaf toughness and phenolics among species in contrasting environments of Australia and New Caledonia. Ann Bot. 2009;103(5):757-67.

31. Steward JL, Keeler KH. Are there trade-offs among antiherbivore defenses in Ipomoea (Convolvulaceae). Oikos. 1988:53(1):79-86.

32. Twigg LE, Socha LV. Physical versus chemical defence mechanisms in toxic Gastrolobium. Oecologia. 1996;108(1):21-8.

33. Moles AT, Peco B, Wallis IR, Foley WJ, Poore AGB, Seabloom EW, Vesk PA, Bisigato AJ, Cella-Pizarro L, Clark CJ, et al. Correlations between physical and chemical defences in plants: tradeoffs, syndromes, or just many different ways to skin a herbivorous cat? New Phytol. 2013;198(1):252-63.

34. Cannon $\mathrm{CH}$, Manos PS. Phylogeography of the southeast Asian stone oaks (Lithocarpus). J Biogeogr. 2003;30(2):211-26.

35. Nixon KC. Origins of Fagaceae. In: Crane PR, Blackmore S, editors. Evolution Systematics and Fossil History of the Hamamelidae: Higher Hamamelidae, vol. 2. Oxford: Clarendon; 1989. p. 436-506.

36. Manos PS, Zhou ZK, Cannon CH. Systematics of Fagaceae: phylogenetic tests of reproductive trait evolution. Int J Plant Sci. 2001;162(6):1361-79.

37. Oh S-H, Manos PS. Molecular phylogenetics and cupule evolution in Fagaceae as inferred from nuclear CRABS CLAW sequences. Taxon. 2008; 57(2):434-51.

38. Chen S-C, Cannon CH, Kua C-S, Liu J-J, Galbraith DW. Genome size variation in the Fagaceae and its implications for trees. Tree Genet Genom. 2014; 10(4):977-88.

39. Huang C, Zhang Y, Bruce B: Fagaceae. In: Flora of China. Edited by Zhengyi Y. Wu, Peter H. Raven, vol. 4. Beijing and St. Louis: Science Press and Missouri Botanical Garden Press; 1999: 314-400.

40. Liao JC. Fagaceae. In: Boufford DE, Hsieh CF, Huang TC, Ohashi H, Yang YP, Lu SY, editors. Flora of Taiwan, 2nd ed, vol. 2. 2nd ed. Taipei, Taiwan, R.O.C.: Editorial Committee of the Flora of Taiwan, Department of Botany, National Taiwan University; 1996. p. 51-123.

41. Soepadmo E. Fagaceae. In: van Steenis CGGJ, editor. Flora Malesiana, vol. 7. Leyden, The Netherlands: Noordhoff International Publishing; 1972. p. 265-403.

42. Zhou W, Xia NH. Leaf epidermal features of Lithocarpus (Fagaceae) from China and their systematic significance. Bot J Linn Soc. 2012;168(2):216-28.

43. Deng M, Li QS, Yang ST, Liu YC, Xu J. Comparative morphology of leaf epidermis in the genus Lithocarpus and its implication in leaf epidermal feature evolution in Fagaceae. Plant Syst Evol. 2013;299(3):659-81.

44. Liao P-C, Chao Y-S, Chiang Y-C. Species occurrence, hybridization and speciation in postglacial east and South Asia. In: Çalışkan M, editor. The molecular basis of plant genetic diversity. Croatia: InTech - Open Access Publisher; 2012. p. 33-60.

45. Gagen M, Finsinger W, Wagner-Cremer F, McCarroll D, Loader NJ, Robertson I, Jalkanen R, Young G, Kirchhefer A. Evidence of changing intrinsic wateruse efficiency under rising atmospheric $\mathrm{CO}_{2}$ concentrations in boreal Fennoscandia from subfossil leaves and tree ring $813 \mathrm{C}$ ratios. Glob Chang Biol. 2011;17(2):1064-72.

46. Gambino G, Perrone I, Gribaudo I. A rapid and effective method for RNA extraction from different tissues of grapevine and other woody plants. Phytochem Anal. 2008;19(6):520-5.

47. Hall TA. BioEdit: a user-friendly biological sequence alignment editor and analysis program for windows 95/98/NT. Nucleic Acids Symp Ser. 1999;41: 95-8.

48. Tamura K, Stecher G, Peterson D, Filipski A, Kumar S. MEGA6: molecular evolutionary genetics analysis version 6.0. Mol Biol Evol. 2013;30(12):2725-9.

49. Guindon S, Dufayard JF, Lefort V, Anisimova M, Hordijk W, Gascuel O. New algorithms and methods to estimate maximum-likelihood phylogenies: assessing the performance of PhyML 3.0. Syst Biol. 2010;59(3):307-21.

50. Ronquist F, Teslenko M, van der Mark P, Ayres DL, Darling A, Hohna S, Larget B, Liu L, Suchard MA, Huelsenbeck JP. MrBayes 3.2: efficient Bayesian phylogenetic inference and model choice across a large model space. Syst Biol. 2012:61(3):539-42.

51. Drummond AJ, Suchard MA, Xie D, Rambaut A. Bayesian phylogenetics with BEAUti and the BEAST 1.7. Mol Biol Evol. 2012;29(8):1969-73.

52. Manos PS, Stanford AM. The historical biogeography of Fagaceae: tracking the tertiary history of temperate and subtropical forests of the northern hemisphere. Int J Plant Sci. 2001;162:S77-93.

53. Tschan GF, Denk T. Trichome types, foliar indumentum and epicuticular wax in the Mediterranean gall oaks, Quercus subsection Galliferae (Fagaceae): implications for taxonomy, ecology and evolution. Bot J Linn Soc. 2012; 169(4):611-44.

54. Liu MQ, Deng M, Zhou ZK. Taxonomic and ecological implications of leaf cuticular morphology in Castanopsis, Castanea, and Chrysolepis. Plant Syst Evol. 2009;283(1):111.

55. Yang ZH. PAML 4: phylogenetic analysis by maximum likelihood. Mol Biol Evol. 2007;24(8):1586-91.

56. Kerstiens G. Water transport in plant cuticles: an update. J Exp Bot. 2006; 57(11):2493-9

57. Blum A. Effective use of water (EUW) and not water-use efficiency (WUE) is the target of crop yield improvement under drought stress. Field Crops Res. 2009;112(2-3):119-23.

58. Sosnovsky Y. Sucking herbivore assemblage composition on greenhouse Ficus correlates with host plant leaf architecture. Arthropod-Plant Inte. 2016; 10(1):55-69.

59. Khan MAU, Shahid AA, Rao AQ, Shahid N, Latif A, Din SU, Husnain T. Defense strategies of cotton against whitefly transmitted CLCuV and Begomoviruses. Advan Life Sci. 2015;2(2):58-66.

60. Wojcicka A. Surface waxes as a plant defense barrier towards grain aphid. Acta Biol Cracov Ser Bot. 2015;57(1):95-103.

61. Lattanzio V, Lattanzio VMT, Cardinali A. Role of phenolics in the resistance mechanisms of plants against fungal pathogens and insects. In: Imperato F, editor. Phytochemistry: Advances in Research. Trivandrum, India: Research Signpost; 2006. p. 23-67.

62. Singleton VL, Rossi JA. Colorimetry of total phenolics with phosphomolybdic-phosphotungstic acid reagents. Am J Enol Viticilt. 1965; 16:144-58.

63. Thomas SC, Martin AR. Carbon content of tree tissues: a synthesis. Forests. 2012;3(2):332-52.

64. Barber NA. Light environment and leaf characteristics affect distribution of Corythuca arcuata (Hemiptera: Tingidae). Environ Entomol. 2010;39(2):492-7.

65. Field C, Merino J, Mooney HA. Compromises between water-use efficiency and nitrogen-use efficiency in 5 species of California evergreens. Oecologia. 1983:60(3):384-9.

66. Niklas KJ, Owens T, Reich PB, Cobb ED. Nitrogen/phosphorus leaf stoichiometry and the scaling of plant growth. Ecol Lett. 2005;8(6):636-42.

67. Norby RJ, Cotrufo MF. Global change: a question of litter quality. Nature. 1998;396(6706):17-8

68. Oren R, Ellsworth DS, Johnsen KH, Phillips N, Ewers BE, Maier C, Schafer KVR, McCarthy H, Hendrey G, McNulty SG, et al. Soil fertility limits carbon sequestration by forest ecosystems in a $\mathrm{CO}_{2}$-enriched atmosphere. Nature. 2001;411(6836):469-72

69. Wigley BJ, Slingsby JA, Díaz S, Bond WJ, Fritz H, Coetsee C. Leaf traits of African woody savanna species across climate and soil fertility gradients: evidence for conservative versus acquisitive resource-use strategies. J Ecol. 2016;104:1357-9.

70. Ariz I, Cruz C, Neves T, Irigoyen JJ, Garcia-Olaverri C, Nogues S, Aparicio-Tejo $\mathrm{PM}$, Aranjuelo I. Leaf $\delta^{15} \mathrm{~N}$ as a physiological indicator of the responsiveness of $\mathrm{N}_{2}$-fixing alfalfa plants to elevated [CO2], temperature and low water availability. Front Plant Sci. 2015;6:574

71. Carter JF, Barwick V, editors. Good practice guide for isotope ratio mass spectrometry. FIRMS: The Forensic Isotope Ratio Mass Spectrometry (FIRMS) Network; 2011.

72. Revell $L$ J. Size-correction and principal components for interspecific comparative studies. Evolution. 2009:63(12):3258-68.

73. Revell LJ. phytools: an R package for phylogenetic comparative biology (and other things). Methods Ecol Evol. 2012;3(2):217-23.

74. Pagel M. Inferring the historical patterns of biological evolution. Nature. 1999:401 (6756):877-84

75. Blomberg SP, Garland T, Ives AR. Testing for phylogenetic signal in comparative data: behavioral traits are more labile. Evolution. 2003:57(4): $717-45$

76. Munkemuller T, Lavergne S, Bzeznik B, Dray S, Jombart T, Schiffers K, Thuiller W. How to measure and test phylogenetic signal. Methods Ecol Evol. 2012; 3(4):743-56

77. Crisp MD, Cook LG. Phylogenetic niche conservatism: what are the underlying evolutionary and ecological causes? New Phytol. 2012;196(3): 681-94.

78. Losos JB. Phylogenetic niche conservatism, phylogenetic signal and the relationship between phylogenetic relatedness and ecological similarity among species. Ecol Lett. 2008;11(10):995-1003. 
79. Phillips SJ, Dudík M. Modeling of species distributions with Maxent: new extensions and a comprehensive evaluation. Ecography. 2008;31(2):161-75.

80. Hijmans RJ, Phillips S, Leathwick J, Elith J. dismo: Species distribution modeling. R package version 08-17 2013. Available online at: http://cran.rproject.org/web/packages/dismo/index.html.

81. Teng LS. Extensional collapse of the northern Taiwan mountain belt. Geology. 1996;24(10):949-52.

82. Chi W-R, Namson J, Suppe J. Stratigraphic record of plate interactions in the coastal range of eastern Taiwan. Mem Geol Soc China. 1981;4:155-94.

83. Wang CS, Huang CP, Ke LY, Chien WJ, Hsu SK, Shyu CT, Cheng WB, Lee CS, Teng LS. Formation of the Taiwan island as a solitary wave along the Eurasian continental plate margin: magnetic and seismological evidence. Terr Atmos Ocean Sci. 2002;13(3):339-54.

84. Degnan JH, Rosenberg NA. Gene tree discordance, phylogenetic inference and the multispecies coalescent. Trends Ecol Evol. 2009;24(6):332-40.

85. Kamthan A, Kamthan M, Azam M, Chakraborty N, Chakraborty S, Datta A. Expression of a fungal sterol desaturase improves tomato drought tolerance, pathogen resistance and nutritional quality. Sci Rep. 2012;2:951.

86. Chen J, Song $Y$, Zhang H, Zhang D. Genome-wide analysis of gene expression in response to drought stress in Populus simonii. Plant Mol Biol Rep. 2013;31(4):946-62.

87. Shepherd T, Griffiths DW. The effects of stress on plant cuticular waxes. New Phytol. 2006:171(3):469-99.

88. Ahmad I, Wainwright SJ. Ecotype differences in leaf surface properties of Agrostis stolonifera from salt marsh, spray zone and inland habitats. New Phytol. 1976;76(2):361-6

89. Pierce S, Maxwell K, Griffiths H, Winter K. Hydrophobic trichome layers and epicuticular wax powders in Bromeliaceae. Am J Bot. 2001;88(8):1371-89.

90. Jakoby MJ, Falkenhan D, Mader MT, Brininstool G, Wischnitzki E, Platz N, Hudson A, Hülskamp M, Larkin J, Schnittger A. Transcriptional profiling of mature Arabidopsis trichomes reveals that NOECK encodes the MIXTA-like transcriptional regulator MYB106. Plant Physiol. 2008 148(3):1583-602.

91. Castillo G, Cruz LL, Tapia-Lopez R, Olmedo-Vicente E, Carmona D, Anaya-Lang AL, Fornoni J, Andraca-Gomez G, Valverde PL, Nunez-Farfan J. Selection mosaic exerted by specialist and generalist herbivores on chemical and physical defense of Datura stramonium. PLoS One. 2014;9(7):e102478.

92. Miranda-Perez A, Castillo G, Hernandez-Cumplido J, Valverde PL, Borbolla M, Cruz LL, Tapia-Lopez R, Fornoni J, Flores-Ortiz CM, Nunez-Farfan J. Natural selection drives chemical resistance of Datura stramonium. Peerj. 2016:4:e1898.

93. Guhling O, Kinzler C, Dreyer M, Bringmann G, Jetter R. Surface composition of myrmecophilic plants: Cuticular wax and glandular trichomes on leaves of Macaranga tanarius. J Chem Ecol. 2005;31(10):2323-41.

94. Crepet WL, Daghlian CP. Castaneoid inflorescences from the middle Eocene of Tennessee and the diagnostic value of pollen (at the subfamily level) in the Fagaceae. Am J Bot. 1980;67(5):739-57.

95. Costa-Saura JM, Martínez-Vilalta J, Spano D, Mereu S. Specific leaf area and hydraulic traits explain niche segregation along an aridity gradient in Mediterranean woody species. Perspect Plant Ecol Evol Syst. 2016;21:23-30.

96. Nardini A, Lo Gullo MA, Trifilo P, Salleo S. The challenge of the Mediterranean climate to plant hydraulics: responses and adaptations. Environ Exp Bot. 2014;103:68-79.

97. Jacques FMB, Guo SX, Su T, Xing YW, Huang YJ, Liu YS, Ferguson DK, Zhou ZK. Quantitative reconstruction of the Late Miocene monsoon climates of Southwest China: a case study of the Lincang flora from Yunnan Province. Palaeogeogr Palaeocl. 2011;304(3-4):318-27.

98. Yao YF, Bruch AA, Mosbrugger V, Li CS. Quantitative reconstruction of Miocene climate patterns and evolution in southern China based on plant fossils. Palaeogeogr Palaeocl. 2011:304(3-4):291-307.

99. Xu JX, Ferguson DK, Li CS, Wang YF. Late Miocene vegetation and climate of the Luhe region in Yunnan, southwestern China. Rev Palaeobot Palynol. 2008;148(1):36-59.

100. Li FJ, Wu NQ, Rousseau DD, Dong YJ, Zhang D, Pei YP. Late Miocene-Pliocene paleoclimatic evolution documented by terrestrial mollusk populations in the western Chinese loess plateau. PLoS One. 2014;9(4):e95754.

101. Zachos J, Pagani M, Sloan L, Thomas E, Billups K. Trends, rhythms, and aberrations in global climate 65 ma to present. Science. 2001;292(5517):686-93.

102. Outlaw DC, Voelker G. Pliocene climatic change in insular Southeast Asia as an engine of diversification in Ficedula flycatchers. J Biogeogr. 2008;35(4): 739-52.
103. Gorog AJ, Sinaga MH, Engstrom MD. Vicariance or dispersal? Historical biogeography of three Sunda shelf murine rodents (Maxomys surifer, Leopoldamys sabanus and Maxomys whiteheadi). Biol J Linn Soc. 2004;81(1): 91-109.

104. Atkins H, Preston J, Cronk QCB. A molecular test of Huxley's line: Cyrtandra (Gesneriaceae) in Borneo and the Philippines. Biol J Linn Soc. 2001;72(1): $143-59$

105. Klaus S, Selvandran S, Goh JW, Wowor D, Brandis D, Koller P, Schubart CD, Streit B, Meier R, Ng PKL, et al. Out of Borneo: Neogene diversification of Sundaic freshwater crabs (Crustacea: Brachyura: Gecarcinucidae: Parathelphusa). J Biogeogr. 2013:40(1):63-74.

106. Susilohadi S, Gaedicke C, Djajadihardja Y. Structures and sedimentary deposition in the Sunda Strait, Indonesia. Tectonophysics. 2009;467(1-4):55-71.

107. Huang $\mathrm{CH}$, Sun RR, Hu Y, Zeng LP, Zhang N, Cai LM, Zhang Q, Koch MA, Al-Shehbaz I, Edger PP, et al. Resolution of Brassicaceae phylogeny using nuclear genes uncovers nested radiations and supports convergent morphological evolution. Mol Biol Evol. 2016:33(2):394-412.

108. McKenna DD, Farrell BD. Tropical forests are both evolutionary cradles and museums of leaf beetle diversity. Proc Natl Acad Sci. 2006;103(29):10947-51.

109. Wahlberg N, Leneveu J, Kodandaramaiah U, Peña C, Nylin S, Freitas AVL, Brower AVZ. Nymphalid butterflies diversify following near demise at the cretaceous/tertiary boundary. Proc R Soc Lond B Biol Sci. 2009:276(1677): 4295-302.

110. Berlocher SH, Bush GL. An electrophoretic analysis of Rhagoletis (Diptera: Tephritidae) phylogeny. Syst Biol. 1982;31(2):136-51.

111. Manzoni S. Integrating plant hydraulics and gas exchange along the drought-response trait spectrum. Tree Physiol. 2014;34(10):1031-4.
Ready to submit your research? Choose BMC and benefit from:

- fast, convenient online submission

- thorough peer review by experienced researchers in your field

- rapid publication on acceptance

- support for research data, including large and complex data types

- gold Open Access which fosters wider collaboration and increased citations

- maximum visibility for your research: over $100 \mathrm{M}$ website views per year

At BMC, research is always in progress.

Learn more biomedcentral.com/submissions 